\title{
Synthesis and Characterization of Transition Metal Ions (Zn, Ni, Mn) Doped $\mathrm{Cofe}_{2} \mathrm{O}_{4}$ Nanoparticles
}

\author{
P.Balakrishnan ${ }^{1}$, P.Veluchamy ${ }^{2} *$ \\ ${ }^{1}$ Department of Physics, Annamalai University, Annamalainagar-608002, Tamil Nadu, India \\ ${ }^{2}$ Department of Enggnearing Physics [FEAT], Annamalai University, Annamalainagar-608002, Tamil Nadu, \\ India
}

\begin{abstract}
The Nanopowders of $\mathrm{Zn}, \mathrm{Ni}$, and $\mathrm{Mn}$ doped $\mathrm{CoFe}_{2} \mathrm{O}_{4}$ nanopowders via sol-gel method processing at pH of 10.3. The synthesized nanopowders are annealed at $700^{\circ} \mathrm{C}$ for $2 \mathrm{hrs}$. The average crystallite size was investigated by using Debye-Scherrer's formula and it was found in the values of 48.35 and $20.93 \mathrm{~nm}, 45.77$ and $8.51 \mathrm{~nm}$ and 49.45 and $43.74 \mathrm{~nm}$ from the XRD patterns of $\mathrm{Zn}$, Ni and $\mathrm{Mn}(1 \%$ and $10 \%)$ doped $\mathrm{CoFe}_{2} \mathrm{O}_{4}$ nanoparticles respectively. SEM measurements have revealed that the nanoparticles exhibit large grain structures having different morphology with soft agglomerations. The elemental analysis as obtained from the energy dispersive X-ray spectroscopy (EDAX) measurement is in close agreement with the expected composition from the stoichiometry of the reactant solutions. FT-IR study showed the main absorption bands corresponding to the tetrahedral and octahedral stretching vibrations. The magnetic properties of all the synthesized $\mathrm{Zn}, \mathrm{Ni}$, and $\mathrm{Mn}$ doped $\mathrm{CoFe}_{2} \mathrm{O}_{4}$ nanoparticles were studied by (VSM) at room temperature. The Saturation magnetization and coercive field are strongly dependent on the various levels of doping concentrations. It is noted that the sample Saturation magnetization (Ms) and Remanent magnetization (Mr) and Coercivity $(\mathrm{Hc})$ values, the room temperature hysterises loop of $(1 \%$ and $10 \%)$ of $\mathrm{Zn}, \mathrm{Ni}$, and $\mathrm{Mn}$ doped $\mathrm{CoFe}_{2} \mathrm{O}_{4}$ nanoparticles were in the range of 0.28 and $1.17,0.27$ and $1.33,0.28$ and $2.0 \mathrm{emu} / \mathrm{g}$ and 3.16 and $0.37,4.18$ and 0.47, 2.89 and $0.48 \mathrm{emu} / \mathrm{g}$ and 92.14 and $612.09,132.57$ and 849.90, 75.74 and 193.65 Oe respectively. It can be observed that while increasing the doping concentration the saturation magnetization and Coercivity gets increases simultaneously the remanent magnetization gets decreases for all the three dopants.
\end{abstract}

Keywords: Nanoparticles, Magnetic Properties, Vibrating Sample Magnetometer, FT-IR, Sol-gel.

\section{Introduction}

$\mathrm{CoFe}_{2} \mathrm{O}_{4}$ as a type of magnetic materials, has long been of intensive importance in the fundamental sciences and technological applications in various fields of electronics (Sugimoto et al., 1999), photo magnetism (Giri et al., 2002), catalysis (Mathew et al., 2004), ferrofluids (Jacintho et al., 2009), hyperthermia (Pradhan et al., 2007), cancer therapy (Sincai et al., 2001), and molecular imaging agents in magnetic resonance imaging (MRI) (Lee et al., 2007). The applications of $\mathrm{CoFe}_{2} \mathrm{O}_{4}$ are strongly influenced by its magnetic properties. Various preparation techniques have been accordingly developed to produce $\mathrm{CoFe}_{2} \mathrm{O}_{4}$ nanoparticles including chemical co-precipitation (Zi et al., 2009, Gnanaprakash et al., 2007, Qu et al., 2006), microemulsion (Li et al., 2003, Mathew et al., 2007), sol-gel method (Monte mayor et al., 2007, He et al.,), hydrothermal (Kasapoglu et al 2007, Zhao et al., 2008), solvothermal (Liu et al., 2007), organic precursor method (Rashad et al., 2008, Toksha et al., 2008), ball milling (Chinnasamy et al., 2000, Khedr et al., 2006), forced hydrolysis in a polyol medium (Wang et al., 2008, BenTahar et al., 2008), mechanochemical method (Yang et al., 2004, Shi et al., 2000), sonochemical (Shafi et al., 1997) and complexometric synthesis (Thang et al., 2005).

Among these preparation methods, the sol-gel method has recently attracted more interest because of the fact that it has the advantages of cheap precursors, simple preparation and a resulting ultrafine particle (Crider et al., 1982, Madani et al., 2012). It is a unique combination of the combustion and the chemical gelation processes. This method has been used to control the size and morphology of nanoparticles determining the structural and magnetic properties. The process gives a homogeneous powder with a narrow size distribution and requires low energy (Khorrami et al., 2011). Due to these advantages, the sol-gel method is vastly used to prepare the magnetic nanoparticles.

In this chapter, the doping effect of $\mathrm{Zn}, \mathrm{Ni}$ and $\mathrm{Mn}$ in $\mathrm{CoFe}_{2} \mathrm{O}_{4}$ on structural and magnetic properties have been synthesized using sol-gel method. The X-ray powder diffractometry (XRD) confirms the formation of structure and morphological analyses have been done by Scanning Electron Microscopy (SEM) and the chemical composition of the samples was investigated by Energy dispersive spectroscopy (EDAX). The Fourier Transform Infrared Spectroscopy (FT-IR) is used to identify the stretching and bending frequencies of octahedral and tetrahedral occupant. The effect of magnetic properties for the synthesized samples with various levels of doping concentrations was studied using Vibrating Sample Magnetometer (VSM). 


\subsection{Chemicals}

\section{Experimental Detail}

Cobalt Nitrate $\mathrm{Co}\left(\mathrm{NO}_{3}\right)_{2} \cdot 6 \mathrm{H}_{2} \mathrm{O}$ and Ferric Nitrate $\mathrm{Fe}\left(\mathrm{NO}_{3}\right)_{3} \cdot 9 \mathrm{H}_{2} \mathrm{O}$ of analytical grade were used to prepare magnetite nanoparticles and they were obtained from Finar chemicals corporation. The reagents were used without further purification.

\subsection{Synthesis of $\mathrm{CoFe}_{2} \mathrm{O}_{4}$ magnetic nanoparticles}

The process for synthesizing nearly monodisperse $\mathrm{CoFe}_{2} \mathrm{O}_{4}$ nanoparticles at room temperature was carried out as follows: In a typical synthesis, Cobalt Nitrate $\left(\mathrm{Co}\left(\mathrm{NO}_{3}\right)_{2} \cdot 6 \mathrm{H}_{2} \mathrm{O}\right)$ and Ferric Nitrate $(\mathrm{Fe}$ $\left.\left(\mathrm{NO}_{3}\right)_{3} .9 \mathrm{H}_{2} \mathrm{O}\right)$ were mixed with 2-Methoxyethanol under constant magnetic stirring for approximately few mints. Then, $\mathrm{NH}_{3}$ was added to the precursor solution in order to maintain the $\mathrm{pH}$ of the solution to 10.3. The acetic acid and ethylene glycol with 1:1 molar ratio were added to the solution. After continuous stirring of 4 hours at $80^{\circ} \mathrm{C}$, the clear sol was completely turned to a gel. Then, the gel was dried and grinded into powders. After that, the powder was annealed at $700^{\circ} \mathrm{C}$ for $2 \mathrm{hrs}$ in furnace under air atmosphere. Finally, the synthesized $\mathrm{CoFe}_{2} \mathrm{O}_{4}$ nanoparticles were characterized and analyses.

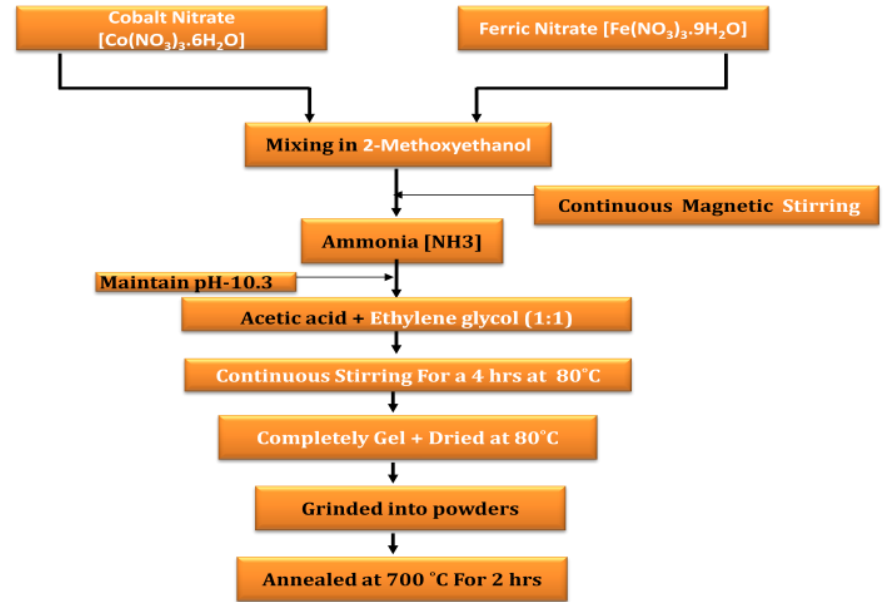

Figure 1: Flow chart showing sol-gel method in synthesis of $\mathrm{CoFe}_{2} \mathrm{O}_{4}$ Magnetic Nanoparticles

\section{Results and Discussion}

\subsection{XRD studies of synthesized powders}

Figure 2 (A-F) shows the XRD pattern for the transition metal ions doped $\mathrm{CoFe}_{2} \mathrm{O}_{4}$ nanoparticles prepared at room temperature and subsequently dried at $80{ }^{\circ} \mathrm{C}$ and annealed at $700{ }^{\circ} \mathrm{C}$ respectively. The miller indices (h k l) planes help us to identify the obtained powders. The XRD pattern shows the characteristic peaks of $\mathrm{CoFe}_{2} \mathrm{O}_{4}$ nanoparticles as it shows the following reflection planes such as (2 20 ), (3 111$)$, (4 $\left.\begin{array}{lll}4 & 0 & 0\end{array}\right)$ and (5 31 1) for all the prepared samples. These planes indicate the formation of a cubic structure (Kasapoglu et al., 2007). All XRD peaks are in good agreement with the JCPDS file No: 22-1086. The average grain size of the samples are calculated using the Debye-Scherrer's formula equation,

\section{$D=k \boldsymbol{N} \beta \cos \theta$}

Where $\lambda$ is the $X$-ray wavelength, $K$ is dimensionless shape factor, $\theta$ is the Bragg angle, $\beta$ is the full width of the diffraction line at the half maximum intensity (FWHM).

In Figure $2(\mathbf{A} \& \mathbf{B})$ shows the XRD patterns $(1 \%$ and $10 \%)$ of $\mathrm{Zn}$ doped $\mathrm{CoFe}_{2} \mathrm{O}_{4}$ nanoparticles respectively. The average crystallite sizes are calculated using Debye-Scherrer's formula and it was found to be 48.35 and $20.93 \mathrm{~nm}$ for $1 \%$ and $10 \%$ of $\mathrm{Zn}$ doped nanoparticles respectively. It can be observed that, while 10 $\%$ of $\mathrm{Zn}$ doped sample gets reducing particle size. In Figure $2(\mathbf{C} \& \mathbf{D})$ represents the XRD patterns of Ni doped $\mathrm{CoFe}_{2} \mathrm{O}_{4}$ nanoparticles with weight percentages of $1 \%$ and $10 \%$. The average crystallite sizes are calculated using Debye-Scherrer's formula and it was found to be 45.77 and $8.51 \mathrm{~nm}$ for $1 \%$ and $10 \%$ of Ni doped nanoparticles respectively. The XRD patterns of $\mathrm{Mn}(1 \%$ and $10 \%)$ doped $\mathrm{CoFe}_{2} \mathrm{O}_{4}$ nanoparticles were shown in Figure 2 ( $\mathbf{E} \& \mathbf{F})$. The average crystallite sizes are calculated using Debye-Scherrer's formula (previous chapter) and it was found to be of 49.45 and $43.74 \mathrm{~nm}$ for $1 \%$ and $10 \%$ of $\mathrm{Mn}$ doped nanoparticles respectively.

The crystallite sizes of $\mathrm{Zn}$, $\mathrm{Ni}$ and $\mathrm{Mn}$ doped $\mathrm{CoFe}_{2} \mathrm{O}_{4}$ nanoparticles, samples calculated using the Williamson and Hall method were obtained to be 99.04, 16.24, 35.28, 74.54, $14.93 \mathrm{~nm}$ and $144.43 \mathrm{~nm}$, for the samples at different weight percentage of (1\% and $10 \%)$ of $\mathrm{Zn}$, $\mathrm{Ni}$ and $\mathrm{Mn}$ doped $\mathrm{CoFe}_{2} \mathrm{O}_{4}$ nanoparticles, 
respectively. The strain $\varepsilon$ values were obtained to be $0.00126,0.01138,0.00594,0.01019,0.00334$ and 0.00438 , respectively. The results show that the average crystallite sizes obtained from Scherrer's formula and the Williamson and Hall method show a large variation. This is because of the difference in averaging the particle size distribution.

The $\mathrm{CoFe}_{2} \mathrm{O}_{4}$ particle size was high for all the $\mathrm{Zn}, \mathrm{Ni}$ and $\mathrm{Mn}$ in $1 \%$ of doping concentration. Also, the lower particle size was observed in highly doped concentration (ice, $10 \%$ of $\mathrm{Zn}$, Ni and $\mathrm{Mn}$ doped in $\mathrm{CoFe}_{2} \mathrm{O}_{4}$ nanoparticles). This pattern is only observed by Scherrer's method and not in Williamson and Hall plot method. Hence, it is concluded from the above mentioned results, the particle size gets reduced for $1 \%$ of $\mathrm{Zn}$, Ni and $\mathrm{Mn}$ doped $\mathrm{CoFe}_{2} \mathrm{O}_{4}$ nanoparticles. While the size of this $10 \%$ of $\mathrm{Zn}, \mathrm{Ni}$ and $\mathrm{Mn}$ doped $\mathrm{CoFe}_{2} \mathrm{O}_{4}$ nanoparticles gets increasing particle size.

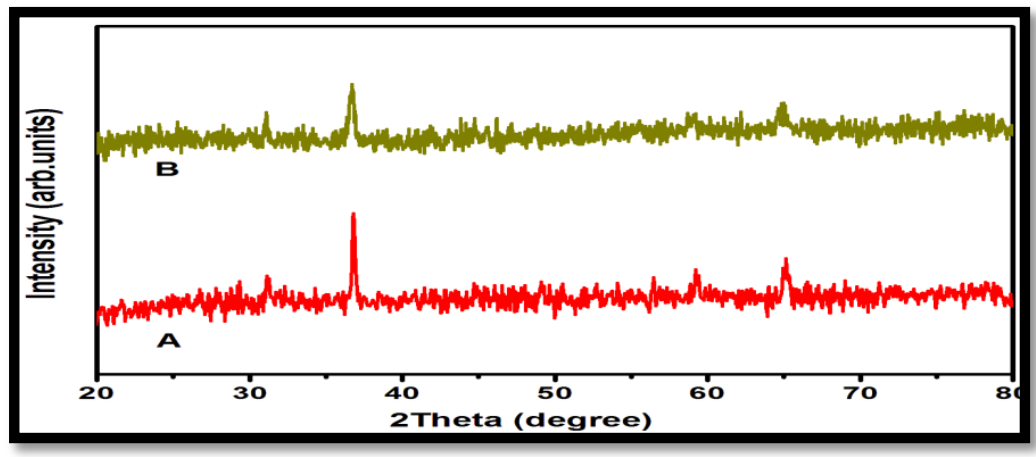

Figure 2 (A \& B) XRD spectra of $1 \%$ and $10 \%$ of $\mathrm{Zn}$ doped $\mathrm{CoFe}_{2} \mathrm{O}_{4}$ nanoparticles

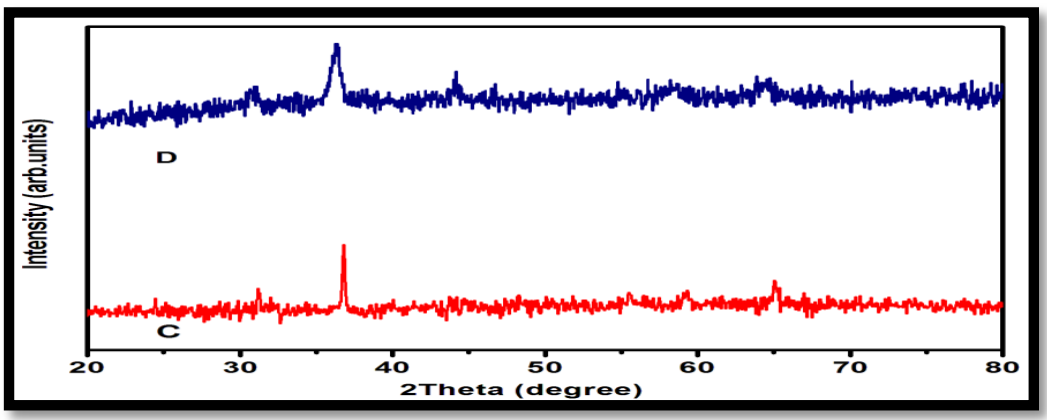

Figure $2(\mathrm{C} \& \mathrm{D}) \mathrm{XRD}$ spectra of $1 \%$ and $10 \%$ of $\mathrm{Ni}$ doped $\mathrm{CoFe}_{2} \mathrm{O}_{4}$ nanoparticles

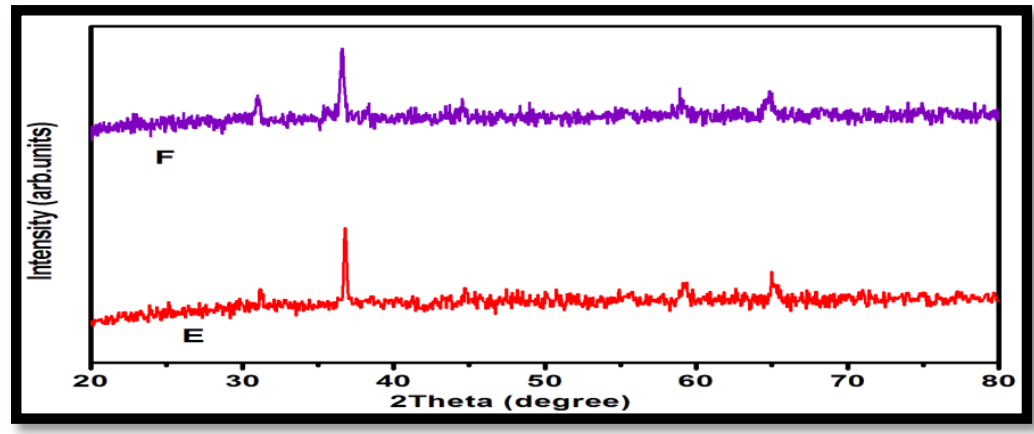

Figure $2(\mathrm{E} \& \mathrm{~F}) \mathrm{XRD}$ spectra of $1 \%$ and $10 \%$ of $\mathrm{Mn}$ doped $\mathrm{CoFe}_{2} \mathrm{O}_{4}$ nanoparticles

Table 1: The particle size, strain, dislocation density of $\mathrm{CoFe}_{2} \mathrm{O}_{4}$ nanoparticles

\begin{tabular}{|c|c|c|c|c|c|}
\hline \multirow[t]{2}{*}{ Sample name } & \multirow{2}{*}{$\begin{array}{l}\text { Percentage (wt \%) } \\
(\mathrm{Co}+\mathrm{Fe}+\mathrm{Zn}, \mathrm{Ni}, \mathrm{Mn})\end{array}$} & \multicolumn{2}{|c|}{ Particle size (nm) } & \multirow[t]{2}{*}{ Strain } & \multirow{2}{*}{$\begin{array}{l}\text { Dislocation } \\
\text { density }\end{array}$} \\
\hline & & $\begin{array}{l}\text { Scherrer } \\
\text { Method }\end{array}$ & $\begin{array}{l}\text { W.H } \\
\text { method }\end{array}$ & & \\
\hline $\mathrm{A}-\mathrm{CoFe}_{2} \mathrm{O}_{4}(\mathrm{Zn})$ & $96+3+1$ & 48.35 & 99.04 & 0.00126 & $7.30925 * 10^{-14}$ \\
\hline $\mathrm{B}-\mathrm{CoFe}_{2} \mathrm{O}_{4}(\mathrm{Zn})$ & $80+10+10$ & 20.93 & 16.24 & 0.01138 & $6.3991 * 10^{-15}$ \\
\hline $\mathrm{C}-\mathrm{CoFe}_{2} \mathrm{O}_{4}(\mathrm{Ni})$ & $96+3+1$ & 45.77 & 35.28 & 0.00594 & $3.24045 * 10^{-15}$ \\
\hline $\mathrm{D}-\mathrm{CoFe}_{2} \mathrm{O}_{4}(\mathrm{Ni})$ & $80+10+10$ & 8.51 & 74.54 & 0.01019 & $1.85879 * 10^{-16}$ \\
\hline $\mathrm{E}-\mathrm{CoFe}_{2} \mathrm{O}_{4}(\mathrm{Mn})$ & $96+3+1$ & 49.45 & 14.93 & 0.00334 & $1.75722 * 10^{-15}$ \\
\hline $\mathrm{F}-\mathrm{CoFe}_{2} \mathrm{O}_{4}(\mathrm{Mn})$ & $80+10+10$ & 43.74 & 144.43 & 0.00438 & $2.45900 * 10^{-15}$ \\
\hline
\end{tabular}



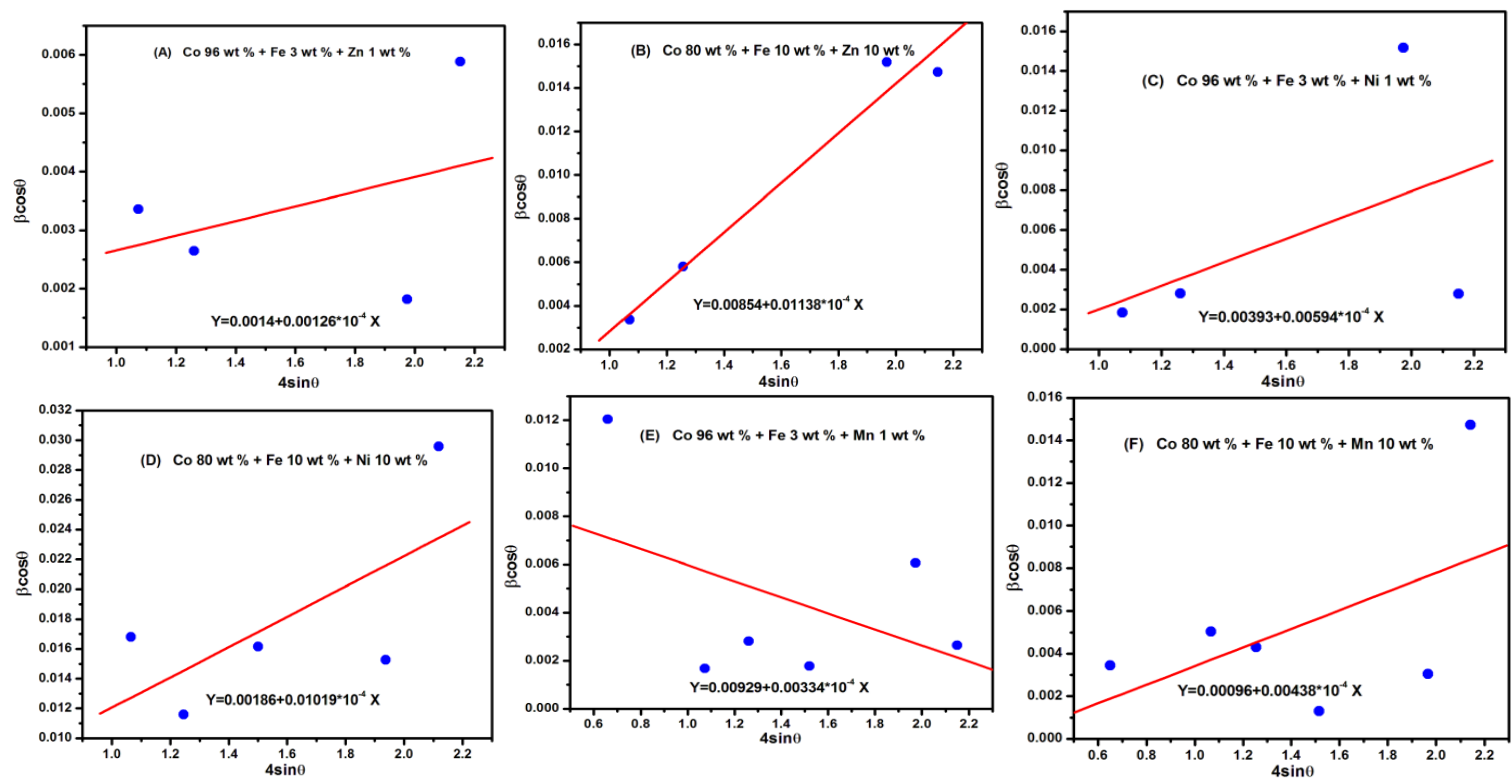

Figure 3 (A - F) W.H analysis of $\mathrm{CoFe}_{2} \mathrm{O}_{4}$ nanoparticles
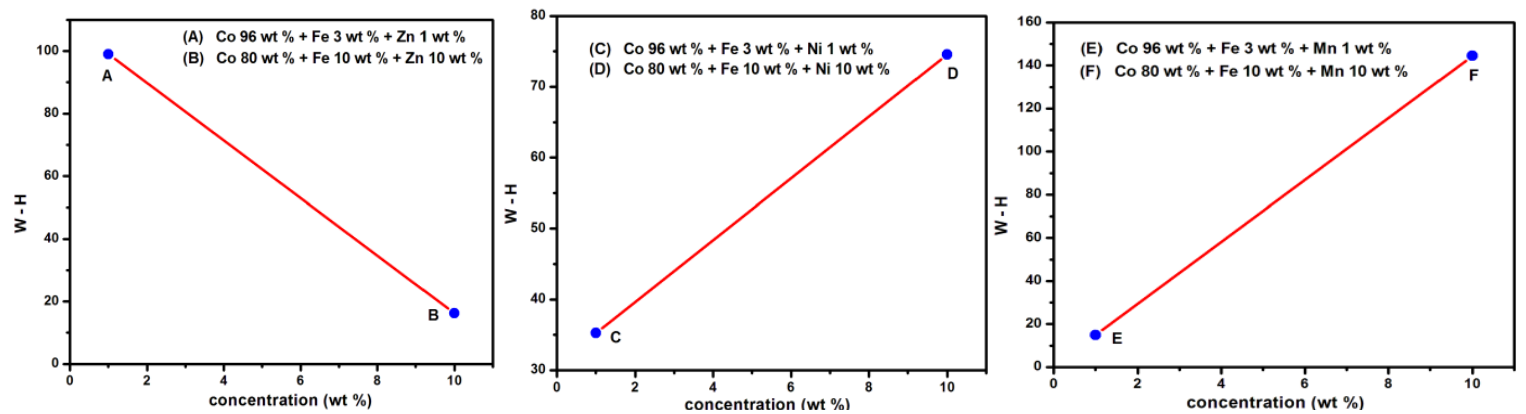

Figure $4(\mathbf{A}-\mathbf{F})$ concentration and $\mathrm{W}-\mathrm{H}$ analysis of $\mathrm{CoFe}_{2} \mathrm{O}_{4}$ nanoparticles
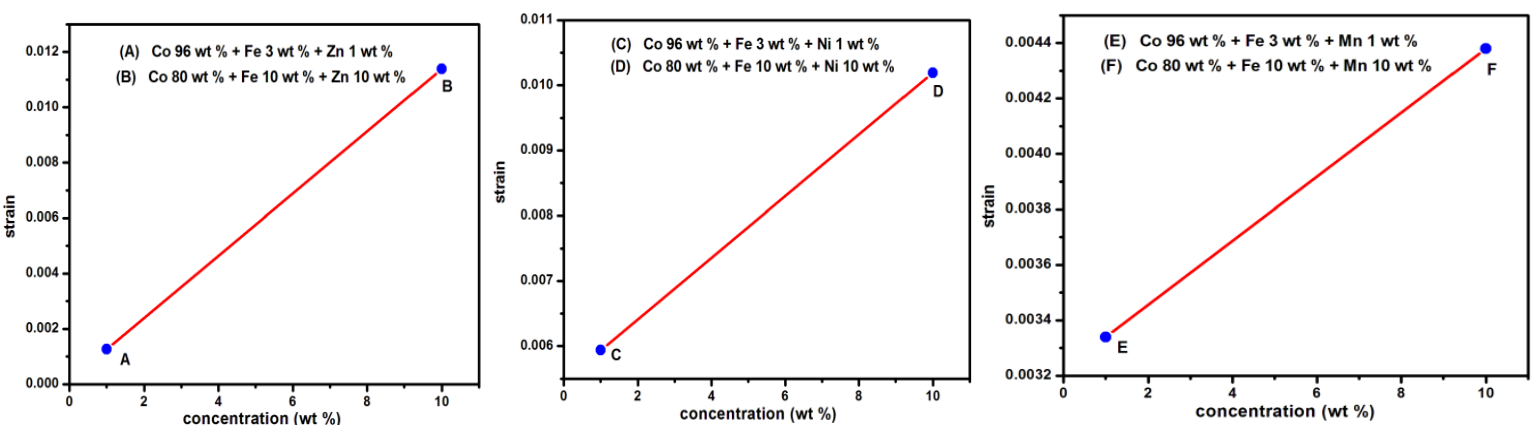

Figure $5(\mathbf{A}-\mathbf{F})$ concentration and strain analysis of $\mathrm{CoFe}_{2} \mathrm{O}_{4}$ nanoparticles

\subsection{Morphological studies by using Scanning Electron Microscope (SEM)}

Figure $6(\mathbf{A ~ \& ~ B})$ shows the SEM images of $1 \%$ and $10 \%$ of $\mathrm{Zn}$ doped $\mathrm{CoFe}_{2} \mathrm{O}_{4}$ nanoparticles annealed at $700^{\circ} \mathrm{C}$ has been visualized from the scanning electron micrograph (SEM). It has been clearly observed that there is a more agglomeration in $1 \%$ of $\mathrm{Zn}$ doped samples comparing to $10 \%$ of doping.

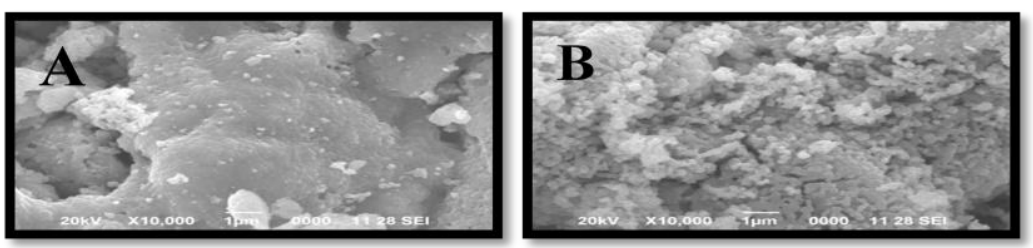

Figure 6 (A \& B) SEM images of $1 \%$ and $10 \%$ of $\mathrm{Zn}$ doped $\mathrm{CoFe}_{2} \mathrm{O}_{4}$ nanoparticles 
Figure $6(\mathbf{C} \& \mathbf{D})$ represents the SEM images of $1 \%$ and $10 \%$ of $\mathrm{Ni}$ doped $\mathrm{CoFe}_{2} \mathrm{O}_{4}$ nanoparticles. Where $1 \%$ of Ni doped samples, some irregular structure has been observed and also $10 \%$ of doped spherical nanoparticles with slight agglomeration have been observed. Hence it's concluded that, $10 \%$ of doped samples may be the optimum level of Ni doping.

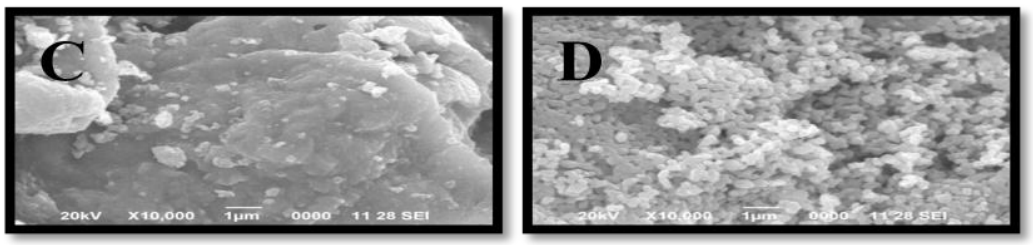

Figure $6(\mathrm{C} \& \mathrm{D}) \mathrm{SEM}$ images of $1 \%$ and $10 \%$ of $\mathrm{Ni}$ doped $\mathrm{CoFe}_{2} \mathrm{O}_{4}$ nanoparticles

SEM images of $1 \%$ and $10 \%$ of $\mathrm{Mn}$ doped $\mathrm{CoFe}_{2} \mathrm{O}_{4}$ nanoparticles are shows in Figure $6(\mathbf{E} \boldsymbol{\&} \mathbf{F})$. It can be clearly observed that an irregular morphological structure was obtained in $1 \%$ of $\mathrm{Mn}$ doped nanoparticles and $10 \%$ of $\mathrm{Mn}$ doped nanoparticles; somewhat the dispersion of nanoparticles has been observed.
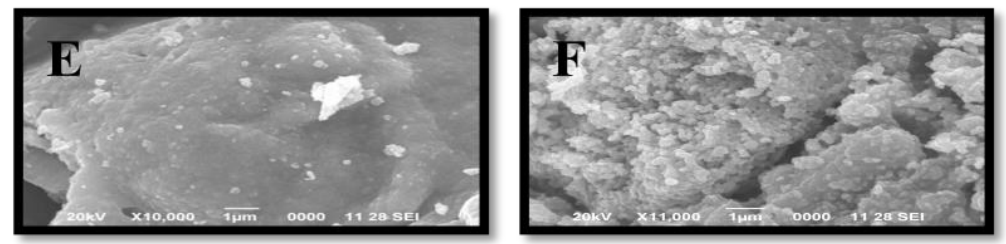

Figure $6(\mathbf{E} \& \mathbf{F})$ SEM images of $1 \%$ and $10 \%$ of $\mathrm{Mn}$ doped $\mathrm{CoFe}_{2} \mathrm{O}_{4}$ nanoparticles

From the SEM images it is obviously concluded that by varying the percentage of $\mathrm{Zn}$, Ni and $\mathrm{Mn}$ doping, the morphological changes were here, obtained. Were also concluded that for all the three doping ( $\mathrm{Zn}$, $\mathrm{Ni}, \mathrm{Mn}$ ) samples $10 \%$ of doped samples may be roughly considered as the optimum level for preparing $\mathrm{CoFe}_{2} \mathrm{O}_{4}$ nanoparticles when compared to $1 \%$ of doping.

\subsection{Elemental analysis using Energy Dispersive x-ray spectrometer (EDAX)}

Figure $7(\mathbf{A} \& \mathbf{B})$ shows the EDAX spectrum of $1 \%$ and $10 \%$ of $\mathrm{Zn}$ doped $\mathrm{CoFe}_{2} \mathrm{O}_{4}$ nanoparticles. The EDAX picture confirms the incorporation of $\mathrm{Zn}$ doped into host lattice. The percentage of compounds presence in the sample is given inside the picture in table. The peak at $2.1 \mathrm{keV}$ is due to gold particles (Ragupathi et al., 2013), which is coated on the sample before morphological analyzing.
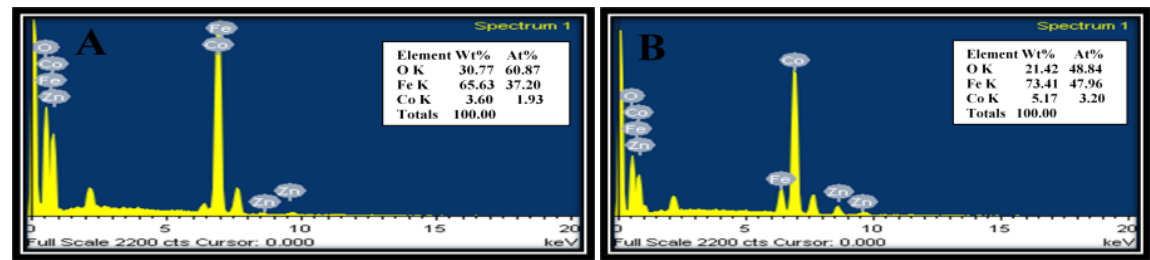

Figure 7(A \& B) EDAX spectrum of $1 \%$ and $10 \%$ of $\mathrm{Zn}$ doped $\mathrm{CoFe}_{2} \mathrm{O}_{4}$ nanoparticles

Figure 7 (C \& D) shows the EDAX spectrum of $1 \%$ and $10 \%$ of $\mathrm{Ni}$ doped $\mathrm{CoFe}_{2} \mathrm{O}_{4}$ nanoparticles. This picture shows incorporation of $\mathrm{Ni}$ doped into the $\mathrm{CoFe}_{2} \mathrm{O}_{4}$ host lattice. The percentage of compounds presence in the sample is given inside the picture in table. The peak at $2.1 \mathrm{keV}$ is represents gold particles (Ragupathi et al., 2013), which is coated on the sample before analyzing of the sample.
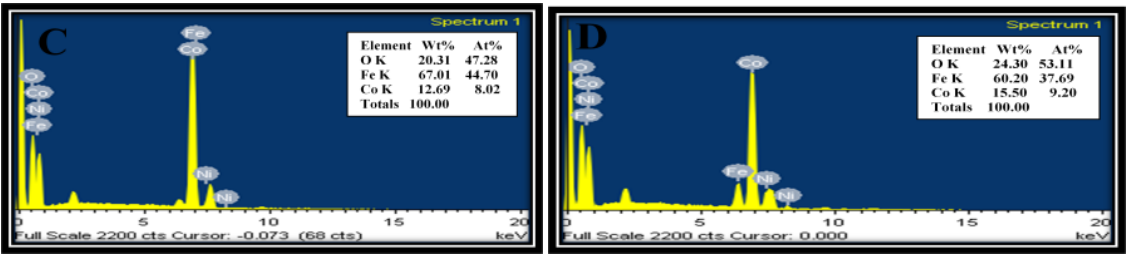

Figure $7\left(\mathbf{C} \&\right.$ D) EDAX spectrum of $1 \%$ and $10 \%$ of $\mathrm{Ni}$ doped $\mathrm{CoFe}_{2} \mathrm{O}_{4}$ nanoparticles 
EDAX spectrum of $1 \%$ and $10 \%$ of $\mathrm{Mn}$ doped $\mathrm{CoFe}_{2} \mathrm{O}_{4}$ nanoparticles. The EDAX are shows in Figure 7 (E \& F) spectrum confirm the incorporation of Mn into the host lattice. The percentage of compounds presence in the sample is given inside the picture in table. The peak at $2.1 \mathrm{keV}$ is due to gold particles (Ragupathi et al., 2013), which is coated on the sample before morphological analyzing.
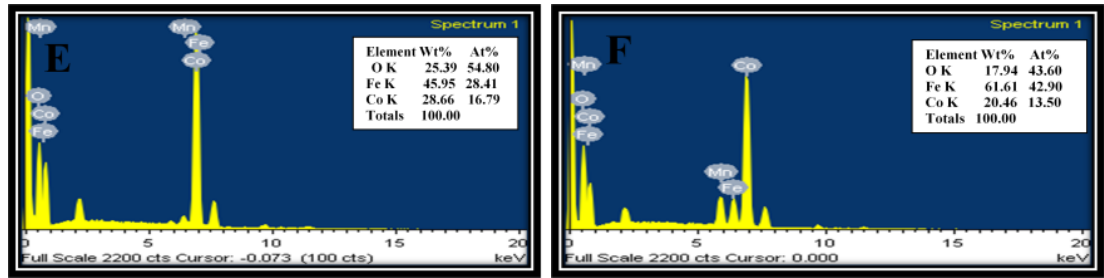

Figure $7\left(\mathbf{E ~ \& ~ F ) ~ E D A X ~ s p e c t r u m ~ o f ~} 1 \%\right.$ and $10 \%$ of $\mathrm{Mn}$ doped $\mathrm{CoFe}_{2} \mathrm{O}_{4}$ nanoparticles

\subsection{Fourier Transforms Infrared Spectroscopy (FT-IR)}

FT-IR spectra are one of the most powerful techniques to analyze the presence of functional groups present in the prepared samples. Using $\mathrm{KBr}$ (Potassium bromide) pellet the Fourier Transform Infrared Spectra of $\mathrm{Zn}, \mathrm{Ni}$ and $\mathrm{Mn}$ doped $\mathrm{CoFe}_{2} \mathrm{O}_{4}$ nanoparticles were recorded in the range of 4000 to $400 \mathrm{~cm}^{-1}$ as shows is Figure 8 (A-F).

Figure $8(\mathbf{A} \& \mathbf{B})$ represents the FT-IR spectra of $1 \%$ and $10 \%$ of $\mathrm{Zn}$ doped $\mathrm{CoFe}_{2} \mathrm{O}_{4}$ nanoparticles. The influence of doping concentration has been observed with decrease in the intensity peak of the highest one is generally observed in the range $659-642 \mathrm{~cm}^{-1}$, and it corresponds to intrinsic stretching vibration of the metal at the tetrahedral site and the lowest band is usually observed in the range of $566-554 \mathrm{~cm}^{-1}$, is assigned to octahedral-metal stretching (Waldron et al., 1955). Also, the adsorption broad band at the range of 3424-3423 $\mathrm{cm}^{-1}$ represents a stretching mode of $-\mathrm{OH}$ groups and $\mathrm{H}_{2} \mathrm{O}$ molecules. The weak adsorption bands around at $1072 \mathrm{~cm}^{-1}$ is due to the asymmetrical stretching vibration of the $\mathrm{O}-\mathrm{H}$ mode and the peak around at $1089 \mathrm{~cm}^{-1}$ is observed the stretching vibration of C-O mode. The peak around at $2923-2922 \mathrm{~cm}^{-1}$ is identified to stretching vibration of $\mathrm{C}=\mathrm{H}$ mode (or) $\mathrm{CH}_{2}$ groups as organic sources in the magnetic nanoparticles for $10 \%$ concentration comparing to $1 \%$.

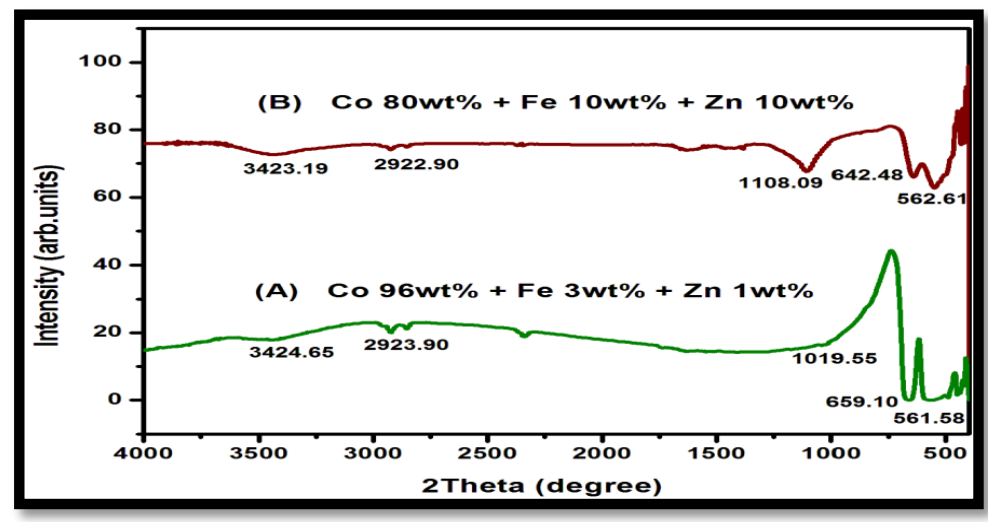

Figure $8(\mathbf{A} \& \mathbf{B})$ FT-IR spectrum of $1 \%$ and $10 \%$ of $\mathrm{Zn}$ doped $\mathrm{CoFe}_{2} \mathrm{O}_{4}$ nanoparticles

Figure $8(\mathbf{C} \& \mathbf{D})$ represents the FT-IR spectra of $1 \%$ and $10 \%$ of $\mathrm{Ni}$ doped $\mathrm{CoFe}_{2} \mathrm{O}_{4}$ nanoparticles. The effect of doping concentration has been observed with decrease in the intensity peak of the highest one is normally observed in the range $658-650 \mathrm{~cm}^{-1}$, and it corresponds to intrinsic stretching vibration of the metal at the tetrahedral site and the lowest band is generally observed in the range of $561-552 \mathrm{~cm}^{-1}$, is assigned to octahedral-metal stretching (Waldron et al., 1955). The adsorption broad band at the range of $3437-3428 \mathrm{~cm}^{-1}$ represents a stretching mode of $-\mathrm{OH}$ groups and $\mathrm{H}_{2} \mathrm{O}$ molecules. The weak adsorption bands around at $1020 \mathrm{~cm}^{-}$ ${ }^{1}$ is due to the asymmetrical stretching vibration of the $\mathrm{O}-\mathrm{H}$ mode and the peak around at $1008 \mathrm{~cm}^{-1}$ is observed the stretching vibration of C-O mode. The peak around at $2927-2923 \mathrm{~cm}^{-1}$ is identified to stretching vibration of $\mathrm{C}=\mathrm{H}$ mode (or) $\mathrm{CH}_{2}$ groups as organic sources in the magnetic nanoparticles for $10 \%$ concentration with comparing to $1 \%$. 


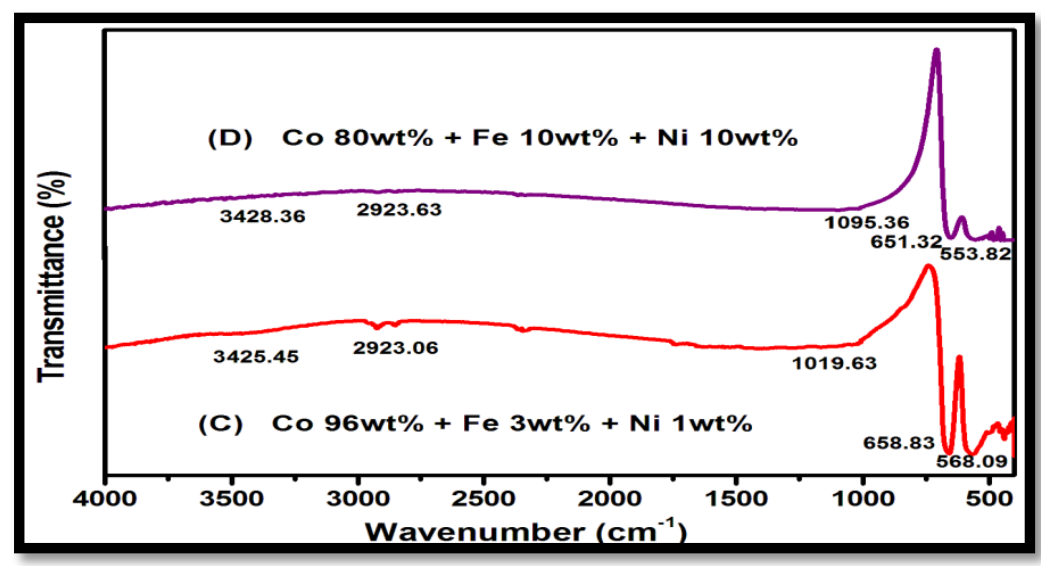

Figure $8\left(\mathbf{C} \&\right.$ D) FT-IR spectrum of $1 \%$ and $10 \%$ of $\mathrm{Ni}$ doped $\mathrm{CoFe}_{2} \mathrm{O}_{4}$ nanoparticles

Figure $8(\mathbf{E} \& \mathbf{F})$ represents the FT-IR spectra of $1 \%$ and $10 \% \mathrm{Mn}$ doped $\mathrm{CoFe}_{2} \mathrm{O}_{4}$ nanoparticles. The influence of doped concentration has been decrease in the intensity peak of the highest one is generally observed in the range $658-650 \mathrm{~cm}^{-1}$, and it corresponds to intrinsic stretching vibration of the metal at the tetrahedral site and the lowest band is usually observed in the range of 566-554 $\mathrm{cm}^{-1}$, is assigned to octahedral-metal stretching (Waldron et al., 1955). Also, the broad adsorption band at the range of $3447-3446 \mathrm{~cm}^{-1}$ represents a stretching mode of $-\mathrm{OH}$ groups and $\mathrm{H}_{2} \mathrm{O}$ molecules. The weak adsorption bands appeared at around $1019 \mathrm{~cm}^{-1}$ is due to the asymmetrical stretching vibration of the $\mathrm{O}-\mathrm{H}$ mode and the peak around at $1108 \mathrm{~cm}^{-1}$ is observed the stretching vibration of C-O mode. The peak around at $2923-2922 \mathrm{~cm}^{-1}$ is identified to stretching vibration of $\mathrm{C}=\mathrm{H}$ mode (or) $\mathrm{CH}_{2}$ groups as organic sources in the magnetic nanoparticles for $10 \%$ concentration Mn doping compared when to $1 \%$.

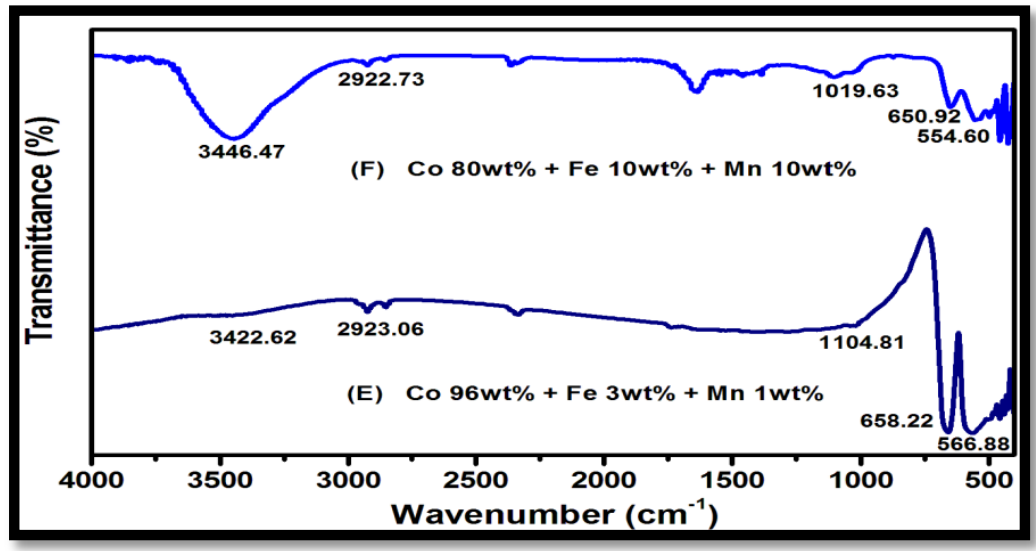

Figure $8(\mathbf{E} \& \mathbf{~ F})$ FT-IR spectrum of $1 \%$ and $10 \%$ of $\mathrm{Mn}$ doped $\mathrm{CoFe}_{2} \mathrm{O}_{4}$ nanoparticles

From the FT-IR spectra it has been observed that, for all this three dopants $1 \%$ of doping concentration, there is not that much changes in the spectra. While $10 \%$ of dopant there is un less intensity peak has been observed in Figure $8(\mathbf{A}-\mathbf{H})$ which shows the influence of higher doping concentration.

\subsection{Vibrating Sample Magnetometer (VSM)}

Figure 9 (A-H) depicts the room temperature hysteresis loop of $\mathrm{Zn}$, Ni and $\mathrm{Mn}$ doped $\mathrm{CoFe}_{2} \mathrm{O}_{4}$ nanoparticles and Table (2) shows the magnetic data obtained. It is observed that the samples annealed at $700^{\circ} \mathrm{C}$ show approximately liner applied field dependence with small S-shape behavior even at $\pm 10 \mathrm{kOe}$ (Zheng Jiao et al., 2008). The magnetic parameters of them determined by the hysteresis loops are given in Table (2). The $\mathrm{CoFe}_{2} \mathrm{O}_{4}$ powders exhibit ferromagnetic properties with a saturated magnetization $\left(\mathrm{M}_{\mathrm{s}}\right)$, Remanent magnetization $\left(\mathrm{M}_{\mathrm{r}}\right)$ and Coercivity $\left(\mathrm{H}_{\mathrm{c}}\right)$ respectively (Sauzedde et al.,). The saturation magnetization values are very much affected by the increase in the temperature as a consequence of the gradual increase in the crystallinity and particle size. A similar behavior has been reported for other magnetic materials (Waje et al., 2010, Ranjith Kumar et al., 2014).

Figure 9 (A \& B) shows hysterises loop of $1 \%$ and $10 \%$ of $\mathrm{Zn}$ doped $\mathrm{CoFe}_{2} \mathrm{O}_{4}$ nanoparticles the room temperature and the obtained magnetic data are given in table (2). it is noted that Figure 9 (A \& B) has low 


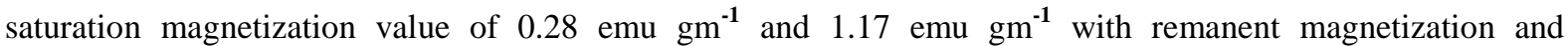
Coercivity values of 3.16 and $0.37 \mathrm{emu} \mathrm{gm}^{-1}$ and 92.14 and $612.09 \mathrm{Oe}$, respectively. The $1 \%$ of Zn doped nanoparticles has superparamagnetic behaviour as shown in Figure 9 (A). As well as $10 \%$ of $\mathrm{Zn}$ doped sample have ferromagnetic behaviour can be observed in Figure 9 (B).

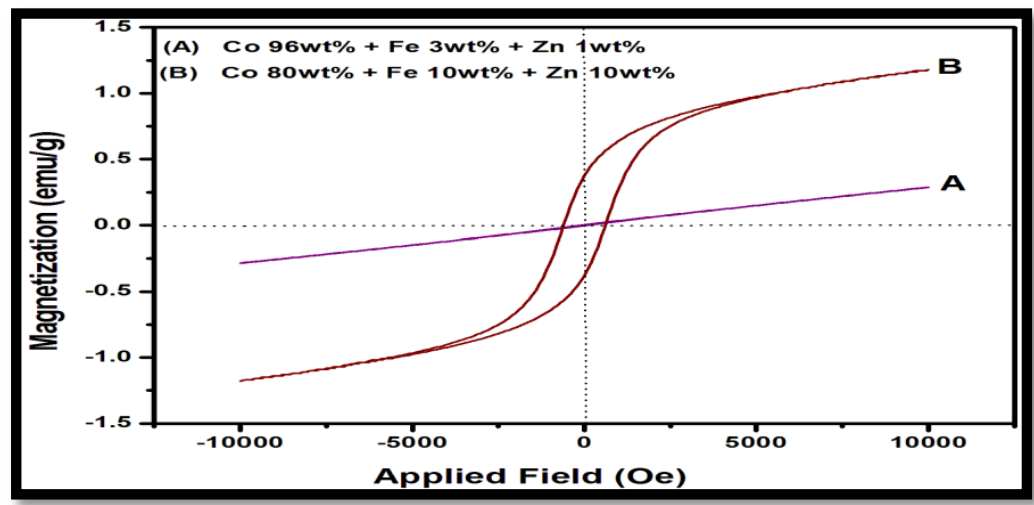

Figure 9 (A \& B) Room temperature hysteresis loops of $1 \%$ and $10 \% \mathrm{Zn}$ doped $\mathrm{CoFe}_{2} \mathrm{O}_{4}$ nanoparticles

Figure $9(\mathbf{C} \& \mathbf{D})$ shows the room temperature hysterises loop of $1 \%$ and $10 \%$ of $\mathrm{Ni}$ doped $\mathrm{CoFe}_{2} \mathrm{O}_{4}$ nanoparticles and the respective magnetic values were given in table (2). It is noted that Figure $9(\mathbf{C} \& \mathbf{D})$ the low saturation magnetization value is $0.27 \mathrm{emu} \mathrm{gm}^{-1}$ and $1.33 \mathrm{emu} \mathrm{gm}^{-1}$ with remanent magnetization and Coercivity values are $4.18,0.47 \mathrm{emu} \mathrm{gm}^{-1}$ and $132.57,849.90 \mathrm{Oe}$, respectively.

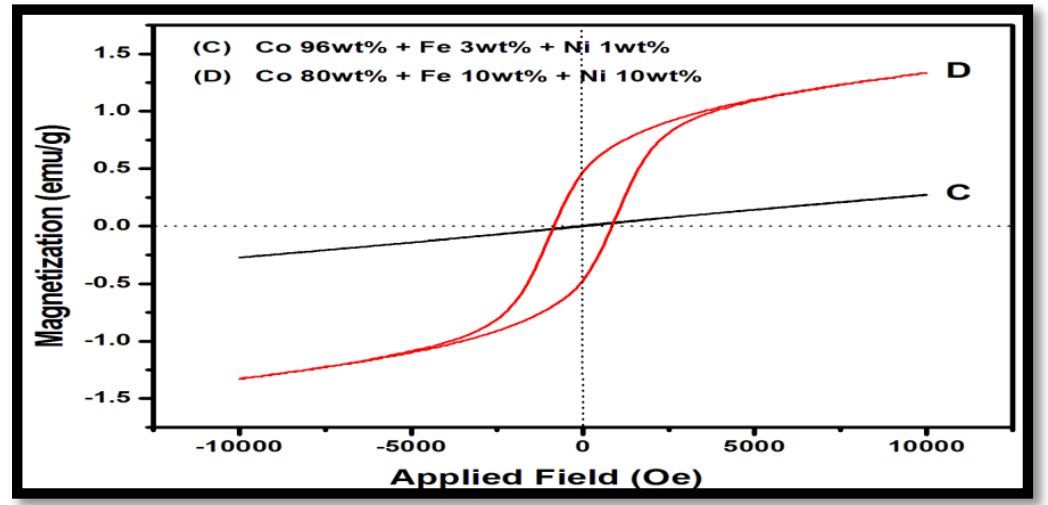

Figure $9(\mathbf{C} \& \mathbf{D})$ Room temperature hysteresis loops of $1 \%$ and $10 \% \mathrm{Zn}$ doped $\mathrm{CoFe}_{2} \mathrm{O}_{4}$ nanoparticles

Figure $9(\mathbf{E} \& \mathbf{F})$ shows the room temperature hysterises loop of $1 \%$ and $10 \%$ of $\mathrm{Mn}$ doped $\mathrm{CoFe}_{2} \mathrm{O}_{4}$ nanoparticles and the obtained magnetic value was given in table (2). It is noted that Figure 9 (E $\boldsymbol{\&} \mathbf{F})$ the low saturation magnetization value is $0.28 \mathrm{emu} \mathrm{gm}^{-1}$ and $2.09 \mathrm{emu} \mathrm{gm}^{-1}$ with remanent magnetization and Coercivity values are $2.89,0.48 \mathrm{emu} \mathrm{gm}^{-1}$ and $75.74,193.65$ Oe, respectively.

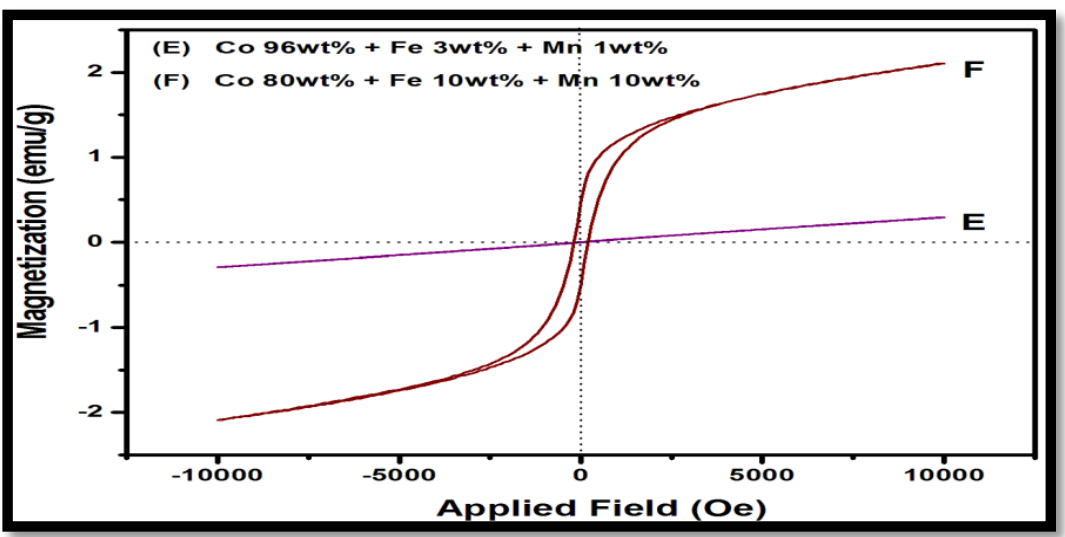

Figure $9(\mathbf{E} \& \mathbf{F})$ Room temperature hysteresis loops of $1 \%$ and $10 \% \mathrm{Zn}$ doped $\mathrm{CoFe}_{2} \mathrm{O}_{4}$ nanoparticles 
From the table (2) it can be observed that while increasing the doping concentration the saturation magnetization and Coercivity increased, simultaneously the remanent magnetization gets decreases for all the three dopants.

Table 2: Magnetic Parameters of synthesized nanoparticles at Room Temperature

\begin{tabular}{|l|l|l|l|}
\hline $\begin{array}{l}\text { Percentage } \\
(\mathbf{W t} \%)\end{array}$ & $\begin{array}{l}\text { Saturation } \\
\text { Magnetization } \\
\mathbf{M}_{\mathbf{s}}(\mathbf{e m u} / \mathbf{g})\end{array}$ & $\begin{array}{l}\text { Remanence } \\
\text { Magnetization } \\
\mathbf{M}_{\mathbf{R}}(\mathbf{e m u} / \mathbf{g})\end{array}$ & $\begin{array}{l}\text { Coercivity } \\
\mathbf{H}_{\mathbf{c}}\left(\mathbf{O}_{\mathbf{e}}\right)\end{array}$ \\
\hline $\begin{array}{l}\mathrm{Co}+\mathrm{Fe}+\mathrm{Zn} \\
(96+3+1 \%)\end{array}$ & 0.2855 & 3.1682 & 92.141 \\
\hline $\begin{array}{l}\mathrm{Co}+\mathrm{Fe}+\mathrm{Zn} \\
(80+10+10 \%)\end{array}$ & 1.1769 & 0.3782 & 612.097 \\
\hline $\begin{array}{l}\mathrm{Co}+\mathrm{Fe}+\mathrm{Ni} \\
(96+3+1 \%)\end{array}$ & 0.2703 & 4.1898 & 132.576 \\
\hline $\begin{array}{l}\mathrm{Co}+\mathrm{Fe}+\mathrm{Ni} \\
(80+10+10 \%)\end{array}$ & 1.3315 & 0.4719 & 849.909 \\
\hline $\begin{array}{l}\mathrm{Co}+\mathrm{Fe}+\mathrm{Mn} \\
(96+3+1 \%)\end{array}$ & 0.2899 & 2.8985 & 75.742 \\
\hline $\begin{array}{l}\mathrm{Co}+\mathrm{Fe}+\mathrm{Mn} \\
(80+10+10 \%)\end{array}$ & 2.0981 & 0.4857 & 193.650 \\
\hline
\end{tabular}
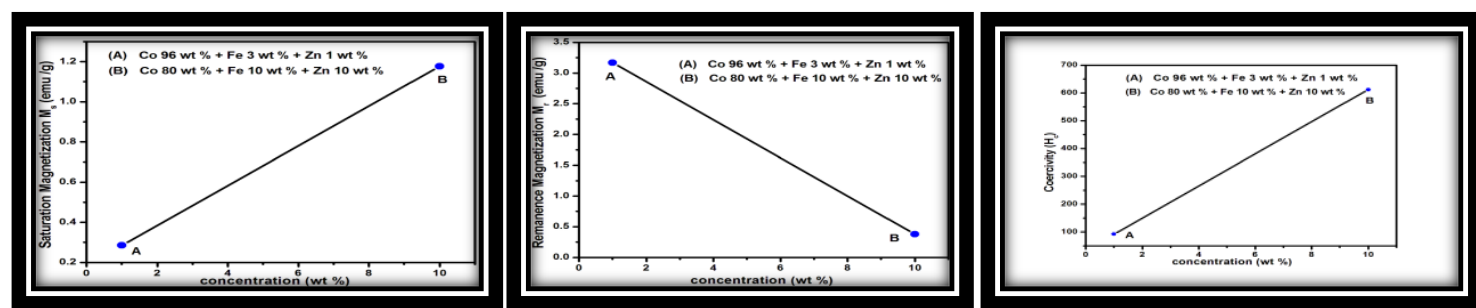

Figure 10 (A) plot concentration Vs saturation magnetization, remanent magnetization and coercivity
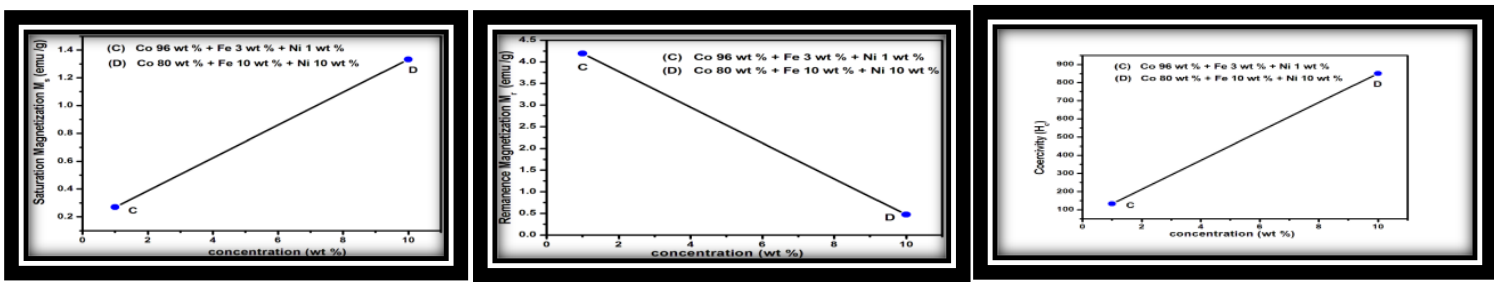

Figure 10 (B) plot concentration Vs saturation magnetization, remanent magnetization and coercivity
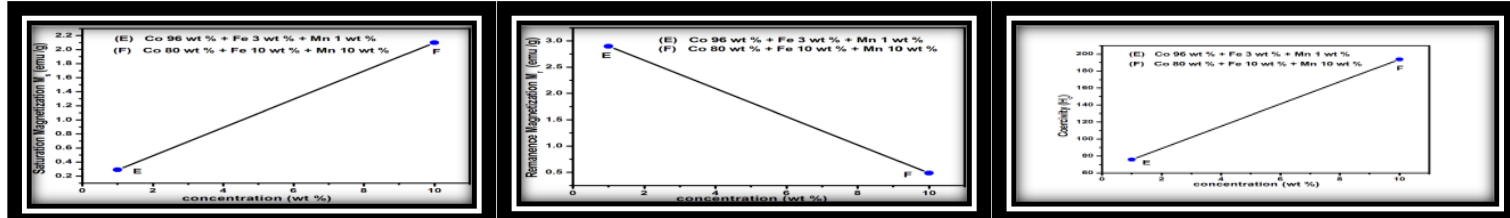

Figure $10(\mathbf{C})$ plot concentration Vs saturation magnetization, remanent magnetization and coercivity

\section{Conclusion}

Nanoferrites of $\mathrm{Zn}$, Ni and $\mathrm{Mn}$ doped $\mathrm{CoFe}_{2} \mathrm{O}_{4}$ were successfully prepared by sol-gel method combined with annealing temperature at $700^{\circ} \mathrm{C}$. The average crystallite sizes are found to be in the range $47.56,38.85$, $58.87,59.38,39.58,46.19,45.29 \mathrm{~nm}$ and $37.22 \mathrm{~nm}$ respectively. The SEM results confirmed the formation with surface of morphologies. The EDAX shows the presence of $\mathrm{Co}, \mathrm{Fe}, \mathrm{Zn}, \mathrm{Ni}, \mathrm{Mn}$ and $\mathrm{O}$. The FT-IR spectra showed bands in range 464-485 $\mathrm{cm}^{-1}$ and $537-578 \mathrm{~cm}^{-1}$ clearly indicating the formation of magnetic nanoparticles. The saturation magnetization $\left(\mathrm{M}_{\mathrm{s}}\right)$ of $\mathrm{Zn}, \mathrm{Ni}$ and $\mathrm{Mn}$ doped $\mathrm{CoFe}_{2} \mathrm{O}_{4}$ nanoferrite varies between 5.57 and $54.14 \mathrm{emu} / \mathrm{g}$ which is better than earlier reported values.

\section{References}

[1]. Sugimoto, M., "The, past present and future of ferrites", J. Am. Ceram. Soc. 82 (1999) 269-80.

[2]. Giri, A. K., Kirkpatrick, E. M., Moongkhamklang, P., Majetich, S. A., "Photo magnetism and structure in cobalt ferrite nanoparticles", Appl. Phys. Lett. 80 (2002) 2341.

[3]. Mathew, T., Shylesh, S., Devassy, B. M., Vijayaraj, M., Satyanarayana, C. V. V., Rao, B. S., Gopinath, C. S., "selective production of orthoalkyl phenols on $\mathrm{Cu}_{0.5} \mathrm{Co}_{0.5} \mathrm{Fe}_{2} \mathrm{O}_{4}$ a study of catalysis and characterization", Appl. Catal. A-Gen. 35 (2004) 273. 
[4]. Jacintho, G. V .M., Brolo, A. G., Corio, P., Suarez, P. A. Z., Rubim J. C., "Structural Investigation of MFe $\mathrm{O}_{4}(\mathrm{M}=\mathrm{Fe}$, Co) Magnetic Fluids", J. Phys. Chem. C 113 (2009) 7684-7691.

[5]. Pradhan, P., Giri, J., Samanta, G., Sarma, H. D., Mishra, K. P., Bellare, J., Banerjee, R., Bahadur, D., "Comparative evaluation of heating ability and biocompatibility of different ferrite-based magnetic fluids for hyperthermia application", J. Biomed. Mater.Res. Part B, Appl. Biomater. 81 (1), (2007) 12-22.

[6]. Sincai, M., Ganga, D., Bica, D., Vekas, L., "The antitumor effect of loco regional magnetic cobalt ferrite in dog mammary adenocarcinoma", J. Magn. Magn. Mater. 225 (2001) 235.

[7]. Lee, J. H., Huh, Y. M., Jun, Y. W., Seo, J. W., Jang, J. T., Song, H. T., Kim, S., Cho, E. J., Yoon, H. G., Suh, J. S., Cheon, J., "Artificially engineered magnetic nanoparticles for ultra-sensitive molecular imaging", Nat. Med. 13 (1), (2007) 95-9.

[8]. Zi, Z., Sun, Y., Zhu, X., Yang, Z., Dai, J., Song, W., "Synthesis and magnetic properties of CoFe $\mathrm{O}_{4}$ ferrite nanoparticles," J. Magn. Magn. Mater. 321 (2009) 1251-1255.

[9]. Gnanaprakash, G., Philip, J., Jayakumar, T., Raj, B., "Effect of digestion time and alkali addition rate on physical properties of magnetite nanoparticles", J. Phys. Chem. B. 111(28), (2007) 7978-86.

[10]. Ayyappan, S., Philip, J., Raj, B., "A facile method to control the size and magnetic properties of $\mathrm{CoFe}_{2} \mathrm{O}_{4}$ nanoparticles", Mater. Chem. Phys. 115 (2009) 712-717.

[11]. Mattei, Y. C., Perez, O. P., "Synthesis of high-coercivity cobalt ferrite nanocrystals", Micro electron. J. 40 (2009) $673-676$.

[12]. Qu, Y., Yang, H., Yang, N., Fan, Y., Zhu, H., Zou, G., "The effect of reaction temperature on the particle size, structure and magnetic properties of co precipitated $\mathrm{CoFe}_{2} \mathrm{O}_{4}$ nanoparticles", Mater. Lett. 60 (2006) 3548-3552.

[13]. Li, X., Kutal, C., "synthesis and characterization of superparamagnetic $\mathrm{Co}_{\mathrm{x}} \mathrm{Fe}_{3-\mathrm{x}} \mathrm{O}_{4}$ nanoparticles", J. Alloys Compds. 349 (2003) 264.

[14]. Moumen, N., Pileni, M. P., "New Syntheses of Cobalt Ferrite Particles in the Range 2-5 nm: Comparison of the Magnetic Properties of the Nanosized Particles in Dispersed Fluid or in Powder Form", Chem. Mater. 8 (5), (1996) 1128-1134.

[15]. Mathew, D. S., Juang, R. S., "An overview of the structure and magnetism of spinel ferrite nanoparticles and their synthesis in microemulsion”, Chem. Eng. J. 129 (2007) 51-65.

[16]. Monte mayor, S. M., Cerda, L. A. G., Lubian, J. R. T., Fernandez, O. S. R., "Comparative study of the synthesis of CoFe $\mathrm{O}_{4}$ and $\mathrm{NiFe}_{2} \mathrm{O}_{4}$ in silica through the polymerized complex route of the sol-gel method", J. Sol-Gel Sci. Technol. 42 (2007) 181-186.

[17]. He, H. C., Ying, M. H., Zhou, J. P., Nan, C. W., J. Electroceram. Doi: 10.1007/ s10832-00792682.

[18]. Kasapoglu, N., Birsoz, B., Baykal, A., Koseoglu, Y., Toprak, M. S., "Synthesis and magnetic properties of octahedral ferrite $\mathrm{Ni}_{x} \mathrm{Co}_{1-x} \mathrm{Fe}_{2} \mathrm{O}_{4}$ nanocrystals", Cent. Eur.J. Chem. 5(2), (2007) 570-580.

[19]. Liu, Q., Sun, J., Long, H., Sun, X., Zhong, X., Xu, Z., "Hydrothermal synthesis of $\mathrm{CoFe}_{2} \mathrm{O}_{4}$ nano platelets and nanoparticles", Mater. Chem. Phys. 108 (2-3), (2008) 269-273.

[20]. Zhao, L., Zhang, H., Xing, Y., Song, S., Yu, S., Shi, W., Guo, X., Yang, J., Lei, Y., Cao, F., "Studies on the magnetism of cobalt ferrite nanocrystals synthesized by hydrothermal method", Solid State Chem. 181 (2008) 245-252.

[21]. Liu, Q., Lai, L., Fu, X., Zhu, F., Sun, J., Rong, H., He, M., Chen, Q., Xu, Z., "Solvothermal synthesis of CoFe ${ }_{2} \mathrm{O}_{4}$ hollow spheres", J. Mater. Sci. 42 (2007) 10113-10117.

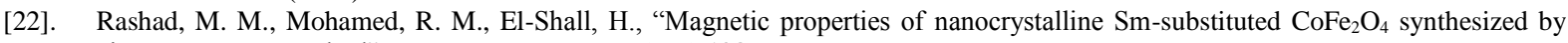
citrate precursor method", J. Mater. Process. Technol. 198 (2008) 139-146.

[23]. Toksha, B. G., Shirsath, S. E., Patange, S. M., Jadhav, K. M., "Structural investigation and Magnetic properties of Cobalt ferrite nanoparticles prepared by So-gel auto combustion method", Solid State Commun. 147 (2008) 479.

[24]. Varma, P. C. R., Manna, R. S., Banerjee, D., Varma, M. R., Suresh, K. G., Nigam, A. K., "Magnetic properties of CoFe ${ }_{2} \mathrm{O}_{4}$ synthesized by solid state, citrate precursor and polymerized complex methods: A comparative study", J. Alloys Compds. $\mathbf{4 5 3}$ (2008) 298-303

[25]. Soibam, I., Phanjoubam, S., Prakash, C., "Mossbauer and magnetic studies of cobalt substituted lithium zinc ferrites prepared by citrate precursor method", J. Alloys Compds. 475 (2009) 328-331.

[26]. Tong, J., Bo, L., Li, Z., Lei, Z., Xia, C., "Magnetic $\mathrm{CoFe}_{2} \mathrm{O}_{4}$ nanocrystals: A novel and efficient heterogeneous catalyst for aerobic oxidation of cyclohexane", Journal of Molecular Catalysis A-Chemical, 307(1-2), (2009) 58-63.

[27]. Chinnasamy, C. N., Narayanasamy, A., Ponpandian, N., Chattopadhyay, K., Guerault, H., Greneche J. M., "Magnetic properties of nanostructure ferrimagnetic zinc ferrite", J. Phy: Condens. Matter 12 (35), (2000) 7795-7805.

[28]. Khedr, M. H., Omar, A. A., Abdel-Moaty, S. A., "Magnetic nanocomposite: Preparation and characterization of Co-ferrite nanoparticles", Colloids Surf. A: Physicochem. Eng. Aspects 281(1), (2006) 8-14.

[29]. Wang, W. W., "Microwave-induced polyol-process synthesis of $\mathrm{MFe}_{2} \mathrm{O}_{4}(\mathrm{M}=\mathrm{Mn}, \mathrm{Co})$ nanoparticles and magnetic property", Mater. Chem. Phys. 108 (2-3), (2008) 227-231.

[30]. Ammar, S., Helfen, A., Jouini, N., "Magnetic properties of ultrafine cobalt ferrite particles synthesized by hydrolysis in a polyol medium", J. Mater. Chem. 11 (2001) 186-192.

[31]. BenTahar, L., Artus, M., Ammar, S., Smiri, L. S., Herbst, F., Vaulay, M. J., Richard, V., Greneche, J. M., Villain, F., Fievet, F., "Magnetic properties of $\mathrm{CoFe}_{1.9} \mathrm{RE}_{0.1} \mathrm{O}_{4}$ nanoparticles ( $\mathrm{RE}=\mathrm{La}, \mathrm{Ce}, \mathrm{Nd}, \mathrm{Sm}, \mathrm{Eu}, \mathrm{Gd}, \mathrm{Tb}, \mathrm{Ho}$ ) prepared in polyol", J. Magn. Magn.Mater. 320 (23), (2008) 3242 -3250.

[32]. Yang, H., Zhang, X., Tang, A., Oiu, G., "Cobalt Ferrite Nanoparticles Prepared by Co precipitation/Mechanochemical Treatment", Chem.Lett. 33 (7), (2004) 826-827.

[33]. Shi, Y., Ding, J., Yin, H., "CoFe $\mathrm{O}_{4}$ Nanoparticles Prepared by the Mechanical Method”, J. Alloys Compds. 308 (1-2), (2000) 2905 .

[34]. Shafi, K. V. P. M., Koltypin, Y., Gedanken, A., Prozorov, R., Balogh, J., Lendvai, J., Felner, I., "Sonochemical Preparation of Nanosized Amorphous $\mathrm{NiFe}_{2} \mathrm{O}_{4}$ Particles", J. Phys. Chem. B 101 (1997) 6409-6414.

[35]. Thang, P. D., Rijnders, G., Blank, D. H. A., "Spinel cobalt ferrite by complexometric synthesis", J. Magn. Magn. Mater. 295 (2005) 251.

[36]. Crider, J. F., "Self-propagating high-temperature synthesis: a soviet method for producing ceramic materials", Ceramics Engineering and Science Proceedings 3 (1982) 519.

[37]. Srivastava, M., Chaubey, S., Animesh, K. O., "Investigation on size dependent structural and magnetic behavior of nickel ferrite nano- particles prepared by sol-gel and hydrothermal methods", Materials Chemistry and Physics 118 (1), (2009) 174-180

[38]. Madani, S. S., Mahmoudzadeh, G., Khorrami, S. A., "Influence of $\mathrm{pH}$ on the characteristics of cobalt ferrite powder prepared by a combination of sol-gel auto-combustion and ultrasonic irradiation techniques", Journal of Ceramic Processing Research 13 (2), (2012) 123-126. 
[39]. Khorrami, S. A., Mahmoudzadeh, G., Madani S. S., Gharib, F., "Effect of calcination temperature on the particle sizes of zinc ferrite prepared by a combination of sol-gel auto combustion and ultra- sonic irradiation techniques", Journal of Ceramic Processing Research 12 (5), (2011) 504-508.

[40]. Kasapoglu, N., Birsoz, B., Baykal, A., Koseoglu, Y., Toprak, M. S., "Synthesis and magnetic properties of octahedral ferrite $\mathrm{Ni}_{\mathrm{x}} \mathrm{Co}_{1-\mathrm{x}} \mathrm{Fe}_{2} \mathrm{O}_{4}$ nanocrystals", Central European Journal of Chemistry 5 (2), (2007) 570-580.

[41]. Guinier, A., "X-ray diffraction in crystals, imperfect crystals, and amorphous bodies", San Francisco, CA, 169 (1963) $209-212$.

[42]. Waldron, R. D., "Infrared spectra of ferrites", Phys. Rev. 99 (1955) 1727-1735.

[43]. Zheng Jiao, Xiang Geng, Minghong Wu, Yong Jiang, Bing Zhao, "Preparation of CoFe $\mathrm{O}_{4}$ nanoparticles by spraying coprecipitation and structure characterization", Colloids and Surface A: Physsicchem. Eng. Aspects (31-34), (2008) 313-314.

[44]. Sauzedde, F., Esmissari, A., Pichot, C., "Hydrophilic magnetic polymer latexes, Adsorption of magnetic iron oxide nanoparticles onto various cationic latexes", Colloid Polymer Sci. 277 (1999) 846-855.

[45]. Waje, S. B., Hashim, M., Wan Yusoff, W. D., Abbas, Z., "Sintering temperature dependence of room temperature magnetic and dielectric properties of $\mathrm{CoFe}_{2} \mathrm{O}_{4}$ prepared using mechanically alloyed nanoparticles", J. Magn. Mater. 322 (2010) 686-691.

[46]. Ranjith Kumar, E., Jayaprakash, R., Sanjay Kumar, "The role of annealing temperature and bio template (egg white) on the structural, morphological and magnetic properties of manganese substituted $\mathrm{MFe}_{2} \mathrm{O}_{4}(\mathrm{M}=\mathrm{Zn}, \mathrm{Cu}, \mathrm{Ni}, \mathrm{Co})$ nanoparticles", J. Magn. Mater. 351 (2014) 70-75. 